\title{
Developing a manual to guide project evaluation for RainWater Cambodia
}

\author{
Klyti Scott \\ Department of Environmental Engineering, RMIT, Melbourne, Australia \\ klyti.scott@hotmail.com
}

\begin{abstract}
The Project Evaluation Manual has been developed to guide the Non-Government Organisation (NGO) RainWater Cambodia through the steps of project evaluation. Ultimately, those conducting the evaluation will make decisions as to what is important in the evaluation but the manual provides a guide. The manual has been written with only post-project evaluation in mind, but it may also be used as a guide for project development and mid-project evaluation. It may also be used to be adapted for use in other organisations or NGOs. The design of this manual was conducted with consideration as to the fact that RainWater Cambodia has limited funding to steer towards project evaluation and limited time scheduled for conducting project evaluations.
\end{abstract}

KEYWORDS: $\quad$ Project evaluation manual, guidelines, RainWater Cambodia, impact assessment.

1

INTRODUCTION

This manual has been written for RainWater Cambodia (RWC) with the support of Engineers Without Borders (EWB) Australia. RWC is a notfor-profit organisation founded in 2003, based in Phnom Penh that aims to address the lack of access to clean drinking water in rural Cambodia. While many projects have been implemented over the past eight years, very little project evaluation has taken place. The main reasons for this are a lack of funding, resources and time. This manual aims to ease project evaluation and make it more accessible to RWC.

Research conducted over three months and a consequent field trip to Cambodia highlighted the need for a simple project evaluation guide suitable for RWC that was more tangible available online guidelines. This manual was developed based on research conducted on project evaluation, a field trip to Cambodia, interviews with EWB in-country volunteer James Oakley and RWC director Kea Pheng, along with three existing evaluation guides: Evaluation of the Development of the Biosecurity Strategy for Victoria (Bennetts 2009); Program Evaluation Training (McGeary 2008), and Water Quality Project Evaluation: A Handbookfor Objectives-Based Evaluation of Water Quality Projects (Ohio State University, n.d) At the heart of this manual's design is a logical stepby-step process by which RainWater Cambodia can evaluate its projects.

The following is a highly condensed version of the complete manual. The full edition can be obtained by contacting Engineers Without Borders Australia (contact details at conclusion of paper), or by contacting the author directly.

\section{METHODOLOGY}

This manual has drawn extensively on work conducted by Clare Bennetts, Julie McGeary and The Ohio State University in their documents Evaluation of the Development of the Biosecurity Strategy for Victoria; Program Evaluation Training and Water Quality Project Evaluation: A Handbook for Objectives-Based Evaluation of Water Quality Projects respectively. This manual is also the product of an investigative report that was conducted to survey literature on project evaluation. The investigative report can be obtained by contacting the author of this manual

\section{EVALUATION}

\section{Step 1 - Getting started}

The first step of the manual details the commencement of evaluation, this involves the gathering of an evaluation team. This section guides the reader through what to consider when gathering a team.

One of the main considerations is who to involve in the evaluation team. The team should consist of as many relevant project stakeholders as possible for RWC these project stakeholders include RWC 
staff, project participants, village health volunteers, commune council members, local entrepreneurs and WASH committees.

Project stakeholders are both the target of and the drive for project evaluation, so interacting effectively with project stakeholders holds the key to a successful evaluation. Actively involving the stakeholders in the evaluation process requires informing them of the benefits of taking part in the process both for the stakeholders themselves and RWC.

Project evaluation provides great opportunity for learning, and for strengthening relationships between stakeholders. Some reasons for conducting Project Evaluation include:

- assessment of project sustainability/suitability

- identification of areas for improvement

- assessment of the social, economic and enviromental impact of the project impact

- to fulfil project accountability requirements

- to understand budget spending

- to report back to donors

- or all of the above

\section{Step 2 - Understanding the project}

Step two guides the reader through understanding the reason for the evaluation, for example, RWC may wish to assess the level of competency of trained local entrepreneurs in supplying demand, to determine whether they are fully equipped to expand and maintain the projects initiated by RWC.

One key questions is 'For whom is the evaluation being conducted?' The answer to this question will help determine the kind of information that will be collected during the evaluation. The possible evaluation audiences include RWC (to improve on their projects), donors (to give them a 'return' on their investment), commune councils (to develop a better understanding of their community's needs), local entrepreneurs (to address any business weaknesses), WASH committees (to assess project impact) and the Cambodian Government (for compliance reasons), or a mixture of any of the above.

Step two recommends 'creating a picture of what success would look like' and to brainstorm ideas of what that encompasses, e.g. increasing access to clean drinking water; improving the health and well-being of women and children; increasing attendance at school. Step two recommends using 'Program Logic' as a way of documenting this picture.

\section{Step 3 - Evaluation barriers/challenges/ limitations}

Step three highlights the importance of addressing potential barriers to the success of the evaluation. This ensures that provisions can be made to overcome those barriers to result in smoother evaluation. Alternatively, it may be decided that barriers for the particular project deem the evaluation unsuitable at that point in time.

The decision not to undertake an evaluation may expenditure costs but project evaluation has great potential to improve projects and subsequently the efficiency at which they run. It is necessary at this point in time to decide whether or not the evaluation should go-ahead. This should be a group decision involving all participants.

\section{Step 4 - Developing key evaluation questions}

Step four guides the reader through developing key evaluation questions (KEQs). KEQs guide the evaluation and are about learning.

Examples of KEQs include the following:

- How can the project be improved?

- What worked for which people and why?

- Are trained entrepreneurs able to supply project demand?

- Is there demand for the project?

- What difference has the project made?

- Have there been any unexpected outcomes as a result of the project?

Including 'Performance Indicators' (PI) in the data collection framework is an excellent way to assess the project on a statistical basis. An example of a PI for RWC would be the number of rain-water harvesting (RWH) systems built and installed by newly trained local entrepreneurs. This gives a quantitative value to success, and can be very useful for assessing projects at a glance.

Performance Indicators are about proving and focus on measurement and are therefore relatively easy to analyse and aggregate. KEQs are about learning and focus on questioning in an effort to provide a qualitative analysis of the PIs. It is crucial to incorporate KEOs and IPs in tandem as measuring only PIs is not recommended, their singular use can be misleading (McGeary, 2008).

\section{Step 5 - Data collection}

Once the KEQs been determined, the data collection method must be chosen. The most suitable data collection method is chosen based upon how appropriately it can answer the KEQs and how suitable it is to the resources available to RWC.

There are many well-known methods for collecting project evaluation data. Taking into account RWC's resources and level of experience with evaluation, the following methods are considered suitable options:

i Asking people individually

- Structured interviews 
- Semi-structure interviews

- Questionnaires: face-to-face, telephone, mail

ii Asking people as a group

- Focus discussion group

iii Physical methods

- Observation

The full edition of this manual describes each method, including advantages and disadvantages, as well as a list of considerations to be aware of when choosing a method.

\section{$4 \quad$ VALIDITY}

Questions in data collection frameworks can always be misinterpreted. One way of testing if questions are being understood properly is to conduct the same pilot test, several times, with the same group of people over a period of weeks. In this way questions which are not understood become apparent from the answers given, and can be adjusted accordingly in an attempt to streamline the framework.

\section{Step 6 - Analysing and reporting results}

Step six guides the reader through the process of reporting and analysing results. It is very important when analysing results to acknowledge and list all known limitations and possible influences. This helps the evaluator see possible explanations for why results appear to be the way they are. Pilot testing is one way of assessing and then justifying the reliability of evaluation results.

Carter McNamara in his Basic Guide to Program Evaluation argues 'there is a strong chance that data about the strengths and weaknesses of a program will not be interpreted fairly if the data [is] analysed by the people responsible for ensuring the program is a good one' (McNamara, n.d).

It may be worthwhile to have someone from outside the organisation analyse the evaluation results to ensure credibility, especially if the evaluation is being conducted for project donors.

\section{Step 7 - Putting Evaluation findings to use}

The final step in this manual is perhaps the most simple to instruct but the most important to implement.

The next step after the compilation of a report is communicating the results to the audience of the evaluation, so that decisions can be made based on those results and action taken in decided areas. A verbal presentation or workshop is the recommended method for communicating results to all project participants, including staff and beneficiaries, as it reaches a wide group of people and is easily absorbed when compared to report reading (McGeary, 2008).

Following a broadcast of the results, workshops should be conducted to find solutions to the problems uncovered in the evaluation, and a plan of action put in place. It is essential that evaluation results be fully utilised, and translated into necessary action.

\section{5}

\section{CONCLUSIONS}

Conducting project evaluation adheres to the age old adage: 'it is better to teach a man how to fish than to give him a fish'. The main aim of evaluation is learning and this manual provides RWC with an avenue for learning and conducting evaluation. Guidelines presented in this manual are based on research of other authors on the subject and the understanding of how RainWater Cambodia operates.

\section{ACKNOWLEDGEMENTS}

Many thanks to Engineers Without Borders, RainWater Cambodia and RMIT university for the opportunity to work on this project, in particular: Julian O'Shea, Pheng Kea, and Edmund Horan. Deepest gratitude must be expressed to Clare Bennetts for guidance; Joe Hurley for inspiration and James Oakley for time and insight.

\section{REFERENCES}

Baker, J 2000, Evaluating the Impact of Development Projects on Poverty, The World Bank, Washington, D.C.

Bakineti, R 2004, 'Using participatory planning processes and learning and action tools to address waste issues in Bikenibeu West, Kiribati', IWP-Pacific Technical Report (International Waters Project), no. 23

Bennetts, C 2009, Evaluation of the Development of the Biosecurity Strategy for Victoria, Biosecurity Victoria, Department of Primary Industries, Melbourne

Chew, C 2008, Pilot study for evaluation of the impacts of rainwater collection systems provided to villagers in rural Cambodia, Melbourne University, Melbourne

Commonwealth of Australia, 2009, NRM MERI Framework, Caring for our Country, Australian Government

Cracknell, E 2000, Evaluating Development Aid: Issues, Problems and Solutions, Sage Publications, New Delhi.

Dart, J \& Roughly, A 2009, Developing a Performance Story Report: User Guide, Caring for our Country, Commonwealth of Australia. 
Davis, J \& Whittington D 1998, " "Participatory" Research for Development Projects: A Comparison of the Community Meeting and Household Survey Techniques', Economic Development and Cultural Change, vol. 47, no. 1, pp. 73-94, viewed 19 March 2011, JSTOR.

EWB, 2001, EWB Innovators Project Brief, Engineers Without Borders Australia, Melbourne

Gomme, J 2002, Impact Assessment Guidelines, WaterAID, London

MacDonald, D 1999, 'Developing guidelines to enhance the evaluation of overseas development projects', Evaluation and Program Planning, vol. 22, no. 2, pp. 163-174, viewed 2 April 2011, Science Direct Full Text

McGeary, J 2008, Program Evaluation Training, Department of Primary Industries, Ellinbank

McInnes, P 2008, Evaluation of the impact of rainwater collection systems for villagers in rural Cambodia, Melbourne University, Melbourne

McNamara, C n.d, Basic Guide to Program Evaluation, Free Management Library, viewed 4 June 2001, $<$ http://managementhelp.org/evaluatn/fnl_eval. htm>
Ohio State University, n.d, 'Water Quality Project Evaluation: A Handbook for Objectives-Based Evaluation of Water Quality Projects', Bulletin Extension, Ohio

Paton, M 2008, Evaluating the Complex: Getting to Maybe, Aid on the Edge of Chaos, viewed 9 April 2011, <http://aidontheedge.info/2009/09/28/ international-conference-on-evaluating-thecomplex-2nd-in-emergent-series-on-complexityand-aid/>

Roberts, D n.d, 'Recreating Experiences: Improving the Validity of Data, Evaluation Journal of Australasia, vol. 4 (new series), nos. 1 \& 2, pp. 44-51

Roughly, A 2009, Developing and using Program Logic in Natural Resource Management, Caring for our Country, Commonwealth of Australia

RWC, 2010, Rainwater Cambodia (RWC), Rainwater Cambodia, Phnom Penh

University of Wisconsin, 2005, Evaluation, Program Development and Evaluation, viewed 6 June 2011, <http://www.uwex.edu/ces/pdande/ evaluation $/>$ 